\title{
LEYES PARA EDUCAR
}

BONIFACIO BARBA

Departamento de Educación/UAA

Jesús Antonio de la Torre Rangel, El derecho a la educación en Aguascalientes, Aguascalientes, Universidad Autónoma de Aguascalientes/Instituto de Educación de Aguascalientes, $1999,100 \mathrm{p}$.

\section{INTRODUCCIÓN}

Di uno estudia la pedagogía, la filosofía - la teoría de la educación se adentra en un ámbito que parece no necesitar leyes, excepto aquellas que por su carácter de enunciados nomotéticos sirven para fundamentar los fines de la acción educativa.

Luego resulta que al estudiar la sociedad, su historia y el derecho uno descubre que todo ello contiene múltiples cuestiones críticas y conflictivas. La razón educativa, esa especie de discurso formativo que en estructuras y perspectivas esencialistas o existencialistas pretende dejar establecidas la necesidad, la posibilidad y la esperanza de la educación, se topa con otra manifestación de los intereses humanos -pedagogía, filosofía y teoría educativas son también expresión del interés- que se convierte en barreras para la educación. Algo humano, sea que lo pensemos como cosa de naturaleza o como algo histórico social, se manifiesta opuesto a las visiones educativas. Para decirlo por ahora brevemente, se abre así una vía de comprensión acerca de la necesidad del derecho en tanto norma jurídica positiva, obligatoria, imperativa. Teleología pedagógica y norma jurídica aparecen como preocupaciones concurrentes.

Mas, en todo esto también se hace presente la política como ámbito de lucha de intereses en la sociedad, como un plano de la convivencia humana del que surge precisamente el derecho: un complejo sistema de saberes, creencias, garantías y obligaciones que se orientan -dentro de 
su propia racionalidad valorativa- por la búsqueda de un horizonte llamado justicia.

Así, si alguien pensara que un libro de leyes es uno sin vida, sólo referido a procederes, litigios, burocracia y trámites, pronto ha de descubrir que no es exclusivamente eso y que tales contenidos no son de los más importantes. En el campo específico de la educación un libro de leyes es una concreción de visiones antropológicas decantadas en lo más profundo de las aspiraciones humanas y en las más recias disputas sociales y políticas. Que nos lo cuente nuestra historia de país independiente.

En otro de sus trabajos, Jesús Antonio de la Torre afirma que el derecho es "un fenómeno social complejo" y para explicar tal cosa dice en seguida que el concepto del derecho es análogo y no unívoco pues "da razón de diversas realidades que no son ni totalmente distintas ni iguales". Hay cuatro realidades que son derecho, nos dice: "las normas o leyes que es el llamado derecho objetivo; las facultades de las personas o grupos sociales llamados derechos subjetivos; la aspiración y las concreciones de justicia; y el conocimiento sistemático de lo anterior, que es la ciencia jurídica".'

$\mathrm{Al}$ realizar su estudio del derecho a la educación en Aguascalientes, de la Torre atiende de hecho los cuatro sentidos del concepto, si bien en las diversas partes de la obra se enfatizan de modo diferente. En mi opinión, predomina la atención del autor al derecho objetivo y subjetivo. Hay un propósito que da estructura al libro: mostrar la presencia, los contenidos y la importancia de la garantía de educación en el estado de Aguascalientes.

DESCRIPCIÓN DE LA OBRA

En su estudio, de la Torre se propone divulgar tanto el conocimiento de las normas que en el pasado regularon la educación como la "normatividad vigente con relación al derecho a recibir educación y el derecho a educar, con sus obligaciones correlativas" (p. 12). El libro está integrado por cuatro capítulos de extensión y alcances distintos.

En el primero encontramos un recuento histórico del derecho a la educación que termina con una referencia a la Constitución Política de Aguascalientes antes de la reforma de su artículo 6o., relativo a la educación, el 19 de marzo de 1997. El capítulo permite observar las mutaciones o evoluciones del derecho, ganando con-

1 Conflictos y uso del derecho (caso Aguascalientes 1977-1988), México, Jus, 1988, p. 13. 
tenido y precisando alcances. Pero también hace posible que se desmitifique la idea lineal de progreso y percibamos la lentitud humana para el establecimiento pleno de la garantía de educación. o como se dice en otro lenguaje, dar un servicio de calidad. Por ejemplo, en la Constitución del Estado de Zacatecas de 1825, vigente para Aguascalientes, se prescribía en el artículo 140:

Los ayuntamientos en los pueblos de su distrito cuidarán especialmente de las escuelas primarias, visitándolas semanariamente para que informen de su estado, auxilios que necesitan para su progreso, $y$ modo de remediar los males que estén a su alcance. (p. 26)

Están ahí dos cuestiones de manera abierta y una veladamente. Las primeras, descentralización y supervisión; y la segunda, el financiamiento. Los tres asuntos son hoy preocupaciones fundamentales en la acción que se propone la eficacia educacional y son problemas serios para las políticas públicas del sector.

El artículo 15 de la actual Ley General de Educación (LGE) permite que los ayuntamientos promuevan y presten servicios educativos; da a los gobiernos estatales la obligación de promover la participación de los ayuntamientos en el mantenimiento de las escuelas y en la provisión de equipo básico a las mismas y faculta a los gobiernos estatales y municipales para "celebrar convenios para coordinar o unificar sus actividades educativas y cumplir de mejor manera las responsabilidades a su cargo".

Debemos entender todo esto en el marco del artículo 12 de la misma LGE, en donde se distribuye la función educativa entre los tres niveles del gobierno, pero atribuyéndose al federal más funciones que a los otros niveles y algunas de suma relevancia en las que no parece justificada la sola función federal.

Un segundo ejemplo es relativo a la acción pedagógica. La Ley Provisional de Instrucción Primaria de Aguascalientes del 31 de octubre de 1897 estableció en su artículo 30 que "el tratamiento a los alumnos será afable, fino y delicado. Se recomienda a los profesores y ayudantes el aseo en su traje y en su persona, como corresponde a la noble misión que desempeñan". Ya don Francisco de Rivero y Gutiérrez, al fundar una escuela de su peculio en 1773-1774, estableció, entre las normas de funcionamiento, ésta:

Juntamente encargo y deseo mucho que dicho maestro procure proceder siempre en el manejo de sus discípulos, más con caridad, amor y cordura, que con rigor de castigos; (menos cuando los delitos lo pidan) pues con equitativa dirección y gobierno, podrá conseguir de todos el general adelanto que apetezco..." (citado en p. 21). 
Hasta aquí el primer capítulo. En el segundo, el más breve de todos, se realiza un análisis del derecho a la educación exponiendo fundamentalmente sus dos sentidos: el de recibir educación o ser educado y el de "determinadas personas o instituciones a educar a otros", es decir, a los que tienen el derecho de recibirla. En lo anterior se encierran asuntos de gran trascendencia algunos de cuyos aspectos son atendidos en los capítulos siguientes y otros requieren de trabajos específicos complementarios de interpretación y de justificación que el autor apenas esboza. Pero lo esencial queda suficientemente precisado: al que tiene el derecho a la educación "se le debe lo que es suyo, lo que le corresponde" (p. 48).

En el siguiente capítulo está contenido algo que quizá es lo más conocido entre los educadores y los juristas, esto es, el derecho a la educación en los textos legales con vigencia en toda la República, ${ }^{2}$ incluyendo diversos instrumentos internacionales. Ciertamente el conjunto documental deja claras dos cosas: por un lado, la indubitable conciencia nacional e internacional respecto del derecho de los individuos (ciudadanos o personas) a la educación como proceso de realización humana; por el otro, la complejidad político-cultural-administrativa de las acciones requeridas para satisfacer el derecho.
La garantía constitucional de que "todo individuo tiene derecho a recibir educación" y sus correlatos en la legislación internacional originan una tarea cuyos bordes, por un lado, parecen inalcanzables, y por el otro están ahí comprometiendo a todo el que jura el desempeño de una función pública y contradiciendo sin ambages la política como utilización de los ciudadanos -las otras personas- y contradiciendo el ejercicio del poder gubernamental como sola dominación burocrática sin estado de derecho que la oriente, regule y valorice.

El capítulo cuarto se ocupa de la legislación educativa vigente en Aguascalientes, siendo el interés central el nuevo artículo 6o. de la Constitución y la Ley de Educación. Es indudable que para el estado de Aguascalientes la aprobación de la reforma y de la nueva ley son acontecimientos de singular trascendencia política y educativa. Establecidos en un contexto de modernización gubernamental y de re-

2 Conviene notar que el autor sólo hace referencia a una de las dos reformas del artículo 30 . de la Constitución Federal durante el gobierno de Carlos Salinas. La primera (28 de enero de 1992), junto con las reformas a los artículos 5 , 24, 27 y 130, desreguló la función educativa; la segunda (05-03-93) hizo obligatoria la educación secundaria. En la p. 39 se hace referencia a la reforma de 1993, si bien parece que atribuyéndole los contenidos de la de 1992. 
forma de la educación, abrieron el horizonte a una renovada comprensión de una tarea social y política por demás justificada, de necesidad imperiosa y atractiva.

Como en el caso de otros instrumentos legales, si vemos éstos en perspectiva filosófica (antropológica, social, política) percibimos una densidad de contenido incuestionable. Así, el artículo 6o. constitucional inicia afirmando que "la educación es un derecho de todas las personas que atiende a las necesidades de su desarrollo y un proceso colectivo de interés general y público". Esto contribuye a eliminar, ideológicamente, las pretendidas propièdades sobre los procesos de la formación humana.

Para de la Torre, este texto es un reconocimiento del derecho a la educación y una asignación de sentido a la misma (p. 74). También destaca el autor otro rasgo novedoso del artículo: al establecer los fines de la educación se afirma que el estado es corresponsable con la sociedad. ¿En qué lo son? No podemos dejar pasar la oportunidad de enunciar estos fines de nuestra labor formativa:

el fomento de la democracia como forma de vida, el respeto a los derechos humanos en el marco de la libertad y la justicia, la mejor convivencia social y colaboración en el trabajo, el desarrollo de individuos libres y autónomos como ciudadanos -con capacidad de juicio y de toma de decisiones responsables- el impulso del desarrollo nacional y estatal, el respeto a la pluralidad social y política, el fomento de la ética, la rectitud, la verdad y la solidaridad y, con peculiar cuidado, la participación en el avance de la ciencia, la tecnología y las humanidades.

Si ante las afirmaciones precedentes no se ha hecho cada quien la pregunta, es inevitable que ésta se formule: ¿cómo hacer efectivo este derecho? ¿Se puede todo? Es complejo el proceso, como ya se afirmó, pues requiere política, inversión, pedagogía y derecho aplicado.

En lo que respecta a la Ley de Educación del Estado de Aguascalientes, de la Torre encuentra que contiene abundantes elementos que establecen el derecho a recibir educación y otras previsiones para asegurar la eficacia de los servicios. Así lo podemos apreciar en el artículo 6o., el cual se complementa en el 10o.: "La educación, además de ser un servicio público prioritario, es un bien social y por tanto es responsabilidad de todos: sociedad y gobierno".

Nuevamente, hay en esto un cambio respecto de nuestras tradiciones jurídicas, políticas y gubernamentales. La educación nos crea a todos, jurídicamente. un deber ético.

También el artículo 65 contiene significativas aportaciones: 
En todos los tipos, niveles y modalidades, el educando será el centro del proceso educativo, cuyo sentido es su formación integral.

El proceso educativo habrá de basarse en la dignidad de la persona (...) En la realización del proceso educativo se ase"gurará al educando la protección y cuidado necesarios para preservar su integridad física, psicológica y social (...) Los planes y programas de estudio... al igual que las normas administrativas y cualquier otro elemento del sistema, se entenderán como medios para el desarrollo del educando y no como fines en sí mismos...

Seguro es que el lector se percata de la trascendencia del texto y se fascina así por la educación y por su sentido de utopía social que no puede mistificarse.

Atendiendo a otro ángulo del derecho educativo, de la Torre señala la ausencia de un aspecto importante y afirma:

El derecho a educar de los padres a sus hijos no aparece explícito en nuestra legislación interna, pero sí, como hemos visto, en la legislación internacional aceptada por México y que constituye derecho obligatorio en todo el territorio del Estado mexicano (pp. 81-82).

En esta cuestión se manifiesta claramente una contradicción que requiere ser resuelta. Implícitamente, el derecho en cuestión aparece en el artículo 78, cuando a propósito de la participación social se establecen otros derechos de los padres, como el de atención al solicitar servicios para sus hijos, de participación en asuntos concernientes al servicio educativo, de asociación, etc.

A causa de nuestros antecedentes y conflictos históricos, es también conveniente mencionar que la LEEA reconoce el ,derecho de la sociedad a educar. Esto tiene dos manifestaciones: primera, se fundamenta el derecho a educar de los particulares y, segunda, se crean las instancias de participación social. Recordemos que la LGE dedica el Capítulo VII a la participación social en la educación estableciendo la innovación de los consejos de participación social. Estos no son aún organismos plenamente activos.

El autor termina este capítulo final de su obra haciendo notar la riqueza de nuestra ley estatal en una cuestión jurídica central, la del contenido de la educación. Esto es materia propia del artículo 12. Desde luego, debemos conocer en todos sus detalles este artículo y apoyar que se ponga en obra a plenitud. El artículo mencionado no sólo recoge legislación federal, sino que aporta particularidades o elementos propios. Recordemos aquí algunos de estos fines, que son en sí mismos una llamada de atención para las prácticas administrativas y pedagógicas: 
Favorecer el desarrollo de facultades para adquirir valores, conocimientos y habilidades," fortalecer "el aprecio por los valores cívicos; infundir el conocimiento y la práctica de la democracia como la forma de gobierno y convivencia que permite a todos participar en la toma de decisiones - para el mejoramiento de la sociedad; promover el valor de la justicia, de la observancia de la ley y de la igualdad de los individuos ante ésta. así como propiciar el conocimiento de los derechos humanos y el respeto a los mismos; hacer conciencia de la necesidad de un aprovechamiento racional de los recursos naturales y de la protección del ambiente; contribuir a que se formen personas autónomas, responsables, equilibradas, respetuosas de la ley (...), con actitudes favorables a la participación, la cooperación y la convivencia civilizadas (...), al desarrollar en los educandos la capacidad de juicio y de toma de decisiones para propiciar la justicia, la libertad y la democracia, así como el aprecio a la ética, la rectitud, la verdad...

Creo que salta a la vista el profundo sentido antropológico y social, y por ende político y económico, que está contenido y garantizado en nuestra legislación educacional.

Para el autor del análisis de nuestra legislación educativa es asimismo importante el hecho de que la LEEA establezca que "toda la educación que se imparta, promueva u ofrezca en el Estado de Aguascalientes tenderá a la calidad", atendien- do a cuatro dimensiones de la misma, como son la relevancia, la eficacia, la equidad y la eficiencia. Así, la ley recoge un importante conjunto de exigencias que proviene del estudio de la realidad educacional y de muchos años de análisis de las políticas públicas y de sus resultados, amén de las tendencias internacionales sobre la cuestión.

$\mathrm{El}$ autor concluye su obra con una reflexión que bien pudiera ser punto de partida: vincula el derecho a la educación con los derechos económicos, sociales $\mathrm{y}$ culturales. Siendo a veces cuestionados. el autor los reconoce como derechos auténticos y fundamentales y, citando a Barba, asienta que "los derechos humanos son el punto de convergencia del derecho a la educación".

\section{CuEstiones PARTiculares}

Si bien las distintas partes de la obra de Jesús Antonio de la Torre son susceptibles de mayor análisis, valoración e in-

$3 \mathrm{Al}$ incorporar los valores de modo tan contundente se corrige otro faltante de nuestra normatividad que ignoraba un componente esencial de la teoría educacional.

4 Bonifacio Barba, Educación para los derechos humanos, México, Fondo de Cultura Económica, 1997, p. 21, citado por de la Torre, p. 21. p. 94 . 
terpretación, el autor fundamentalmente nos expone cómo está legislado el derecho a la educación en Aguascalientes en el contexto de la legislación vigente para todo el país.

Sin embargo, el repaso de nuestra legislación es propicio para poner nuestra atención en varias cuestiones debatidas que conciernen a la eficacia de la ley y su inserción en la vida social y política. Creo que es importante hacer referencia a algunos problemas particulares de nuestra educación y sus leyes. Las presento casi en forma de enumeración pues requieren a su vez mayor análisis y son materia para trabajos amplios.

a) Entrar al mundo del derecho, con su concepción analógica, es entrar tanto a nuestra sociedad real, la que establece el derecho y vive las tensiones de su realización, como a un mundo posible, uno donde el ser humano (personas y sociedad) tienen un horizonte de emancipación y de humanización, que por la vía educativa es atendido con la intención de resolver el problema de la formación del hombre, problema ontológico sí, pero sin duda también social y político, como nos lo deja comprender su expresión jurídica.

Ese mundo humano es actual en su derecho pero está por hacerse en los procesos de interacción humana que llamamos educación; está condicionado a la existencia de una pedagogía jurídica. Aunque la legislación aporta contenidos, no es en sí misma una antropología filosófica ni una exposición ordenada y sistemática de filosofía educacional. De la Torre recurre a Mounier para comentar que el contenido de la educación es "“enseñar a vivir al ser humano plenamente como persona". En esto concurren tanto creencias sobre lo que el ser humano es ya en su dignidad original, existencial, como los aspectos procesales del enseñar a vivir plenamente. Así, tenemos derecho a ser lo que ya somos, personas y no sólo individuos integrados a una colectividad, y tenemos derecho a una experiencia que haga posible la formación en plenitud.

En muchas ocasiones se hace la crítica de que somos un país de leyes incumplidas, que no tocan la realidad. Desde la perspectiva educativa y dado que partimos de la dignidad de la persona, la ley es necesaria porque garantiza un derecho. Si no basta la ley es precisamente porque necesitamos de ese objeto que ella garantiza: la formación.

Por lo anterior, a los dos sentidos del derecho que el autor expone creo que debemos añadir otro: el derecho a la educación significa que tú y yo y cada otro tú y yo necesitamos que el otro se eduque, que sea persona, que en él se haga pleno el derecho a recibir educación. Esta reali- 
zación del derecho es fundamental porque es una condición paradójica para las otras dos. Social, psicológica y jurídicamente el tú es origen del yo.

b) El derecho a ofrecer/dar educación es asunto muy complejo y polémico. Por una parte, no puede existir con independencia y precedencia del derecho a educarse, a ser persona, pues de lo contrario este derecho quedaría supeditado y condicionado.

Tenemos el caso del laicismo. Histórica y políticamente construido, jurídicamente se impone al sujeto que tiene el derecho a recibir educación y la recibe del Estado. Se impone el rasgo del laicismo de un modo que podríamos expresar así desde la perspectiva del Estado: "Tu derecho a recibir educación consiste en que recibas lo que el Estado diga que te educa". ¿Está bien eso? Creo que no, pues exhibe la contienda absurda por las conciencias, nos permite ver a la persona jaloneada entre instituciones y las luchas de ellas por el control social y nos muestra también nuestros lastres históricos.

Este asunto deberá cambiar sobre la base de un cambio valoral de nuestra sociedad y de su vida política. El Estado, si bien es una forma de dominación, jurídicamente es un proyecto de convivencia, y educacionalmente un proyecto de formación. Aquí debemos pues distinguir esta naturaleza del Estado respecto del gobierno, agente responsable de la educación para los fines que a ella misma da el derecho.

c) Veamos otra cosa. La discusión sobre la gratuidad de la educación no está cerrada social y políticamente y yo creo que ni siquiera jurídicamente. Lo que el texto constitucional establece lo hace por decisión política no por un deber ser $a$ priori. En un tiempo decía que toda la educación que impartiera el Estado sería gratuita, ahora ya no lo dice. ¿Es que cambió fundamentalmente nuestra vida social? Tal vez, pero en el sentido de aumentar las desigualdades y la pobreza y en convertir paulatinamente a los servicios educativos en una condición del desarrollo.

Sobre este asunto al menos deben tomarse en cuenta elementos como los siguientes.

- Cuando se juzgó bueno y justo que la educación ahora llamada básica fuese gratuita, había razones de imposibilidad y de pobreza que bien pueden ser válidas ahora en relación a la educación media y superior. ¿Hasta dónde llega el derecho. el de educación y los otros? Un aspirante a educación superior pública proveniente de familia de menores recursos económicos y culturales comparativos, ¿compite realmente en condiciones académicas de 
igualdad de oportunidades en un examen de admisión, como se da por sentado? ¿Son equivalentes las historias académicas al momento del examen cuando han sido diferentes las historias económicas y culturales? La deficiente aptitud académica, ¿es sólo imputable al estudiante o éste es un receptor de malos servicios de un sistema educativo con problemas de eficacia casi consustanciales? Es muy difícil sostener la existencia de una igualdad de oportunidades. Refirámoslo a un caso. La UnAm, en su reforma del Reglamento General de Pagos, plantea una alternativa de solución al problema de la gratuidad basada en la palabra del estudiante, pero tal estudiante necesita, previamente y en todo caso, que su competencia por vía del examen lo sitúe favorablemente en niveles de desempeño comparativos respecto de otros estudiantes.

Ciertamente la realización de la justicia en la sociedad no depende sólo del sistema educativo pero los servicios que éste ofrece se han convertido en nuestro tiempo en un bien de primera necesidad. Si la justicia ha de ser, requiere más caminos y soportes.

- Con cierta independencia de las alternativas respecto a los alcances de la gratuidad, aparece el problema de la formación social y valoral del estudiante de educación media y superior. Siendo estas educaciones bienes escasos en nuestra sociedad, el sistema todo y cada institución deben colocar como objetivo fundamental (es decir, no ritual, ni discursivo, ni incluso complementario) la formación en la responsabilidad y en la solidaridad. Es indispensable que las profesiones tengan curricularmente un poderoso componente ético que promueva en los estudiantes una visión solidaria de su trabajo. Todos tenemos derecho a la educación y tenemos derecho a que los otros se eduquen para que la convivencia tenga el máximo de virtualidad humanizadora 0 , desde otro ángulo, para que el estado de derecho sea perfeccionado conforme a los valores y principios jurídicos que ya lo estructuran.

Además, el problema de la gratuidad no se resolverá en las conciencias y en las arenas políticas donde concurren las clases y los grupos sociales mientras la sociedad y el gobierno no eliminen los terribles grados de corrupción que aún se toleran. Es de dudarse que el gobierno no pueda otorgar a las instituciones de educación superior, por ejemplo, la cantidad de dinero que éstas reúnen a través de las colegiaturas. Si pagar colegiatura es puesto en términos de ser corresponsable, ¿muestra responsabilidad nuestro aparato gubernamental en el uso de los recursos públicos? 
Por otra parte, además de lo aprobado en la UNAM, es decir, el valor de la palabra del alumno, pueden establecerse criterios como éste: proporciones de gratuidad (una forma de dar cauce a las cuotas diferenciales) en relación con diversos indicadores del aprovechamiento por parte del alumno de la oportunidad de educación que la sociedad le ofrece. Este apoyo debe ser evaluado permanentemente. Diríamos, quien no estudia no debe ocupar una plaza; a quien no estudia con responsabilidad, ¿no habrá que decirle que su derecho a educarse lo obliga al deber del esfuerzo?

d) Los diversos problemas jurídicos de la educación y los de naturaleza social, política y económica nos muestran sin duda que la educación misma es una zona de conflicto en donde se disputan las oportunidades culturales y materiales para la vida. Relacionando esto con los contenidos del derecho a la educación, debemos comprender que esencialmente la educación es una educación jurídica, que el modo en que ese proceso social sea experienciado -desde luego no como único ámbito- es definitorio de la identidad de personas, grupos y clases socia- les. Nuestro sistema y cada una de sus instituciones tienen mucho camino por recorrer en cuanto al fin educativo de formar la conciencia de los derechos y las obligaciones. Como hemos visto, todo ello está en los contenidos jurídicamente ya sancionados, pero falta mucha realización pedagógica, social y política.

\section{Palabras finales}

Un texto como el de Jesús Antonio de la Torre, irremediablemente, debe leerse por la relevancia social de lo que compendia. Nos recuerda que la ley existe y que la referida a la educación contiene un germen de realización humana y construye un entorno institucional para ello. Esa ley es necesaria.

Si ahora traemos a la conciencia nuestras circunstancias sociales, políticas y económicas, caeremos en cuenta de que se necesita fortalecer la confianza en la ley y en ese objeto jurídico llamado educación. Es imperativo que nuestra legislación educativa aumente su eficacia como instrumento social y gubernamental en los términos de sus propios fines. 
